\title{
IMPEDANCE BEHAVIOUR AND THE TEMPERATURE DEPENDENCE OF RESISTIVITY OF PAN-BASED CARBON FIBERS
}

\author{
M.M. Abdul-Gader, M.S. Ahmad, R.N. Ahrnad-Bitar, \\ and A.M. Zihlif \\ Department of Physics, University of Jordan, \\ Amman, Jordan.
}

\begin{abstract}
:
The electrical resistivity measured at temperatures from $300 \mathrm{~K}$ to $10 \mathrm{~K}$ and the impedance at $300 \mathrm{~K}$ and up to several $\mathrm{MHz}$ for as-spun high strength PAN-Based Carbon fibers were found to show some interesting behaviour. A maximum at $35 \mathrm{~K}$ was observed in the resistivity which decreases with temperature on either side, in good agreement. with the results reported for heattreated carbon fibers. The ac impedance measurements allowed finding of the real part of the dielectric constant which was found to vary with frequency, $f$, nearly as $f^{-0.7}$ at $f \leqslant 500 \mathrm{KHz}$ and to be almost constant at higher frequencies $(f<10 \mathrm{MHz})$. The imaginary part of the dielectric constant was found to change as $1 / f$ up to $9 \mathrm{MHz}$ suggesting that the ac conductivity is frequency-independent consistent with theoretical predictions.
\end{abstract}

\section{Introductions}

Numeraus models based on the $\mathrm{X}$-ray diffraction end transmission electron micrascopy were proposed for the micro structure of cerban fiters [1-4]. A carbon tibet consists of graphite stfuctural units of crystallites with preferred orientution to the fiber axis. Dether cfystallites are slightly misalignets relative to the tibet axis with 8 misarientation angle of $20^{\circ}-23^{\circ}$, and hence $a$ porous structure is established. The proposod micro structure fot carbon fibets were used successfully to explain the mochanical properties and the electrical tesistivity behnviour under heat treatment. A correlation between elastic maduli and tesistivity was established from the varia= tions in the crystallite size and orlentation under heat trestment [5-8]. Recently, few studies have been reported on the electrical properties of PAN-bBsed carbon fibers as a function of various conditions $[5,9,10]$. Guigon et al. [6] contuded that the abserved electrical tesistivity for a ramily of PAN-based corban fibers correlates wetl with the diameter of the mitrastructural units exterided parallel to the fiber axis. Spain et 8 . [10] obscrved that the low ternetrature resistivity showed a maximum for PAN-bused Celion fibers heat-treated to $\sim 1300^{\circ} \mathrm{C}$. Bright and Singer [9] have studied the electronic properties of mescphuse Pitch-based 
catbon tibers hoat-treated at various temperatures and Rappeneau et al, [11] investigated heat-treated Rigilor $A c$ and $A G$ carbon fibers. Those authors found that the electrical tesistivity of their fibers decreases, in general, with increasing temperature, but no maximum in the tesistivity was abserved.

It is therefore interesting to investigate the tempetature behaviour of resistivity fot as-quin (not heat-treated) PRN-based carbon fibers not only to campare with that reporfed for heat-treated carbon fibers but also to see if it is a common property for all carban fibers. This is the putpose of the present commuracation. Also, good insight into the conduction mechanisms of cartion tibers may be achieved Ly studying thoir dielecttic properties. These can be obtained Itcen ac impedance measurements, In this study the ac impedance was only measured at ran tomperature and as a tunction of frequency up to $1=12 \mathrm{MHz}$.

\section{Experimentals}

\section{Material}

High strength as=spun PAN-based Celion 6000 carbon fibers obtained fram Celanese corpration in U.S.A. were used in this study. Fibers are $7 \mu \mathrm{m}$ in diameter and posses high strain-to-failufe. The tensile strength and modulus far these fihers are 2.73 and $230 \mathrm{GPa}$, respectively, and the predicted misorientation angle of the crystallite is $22^{\circ}[4-6]$.

\section{Resistivily measurements}

Measurements of langitudinal resistance were made on a single carbon filament using the ac-four probe method. This method has the advantage of minimizing the noise and pick-up signals and of high precision. A single fibet af nhaut $20 \mathrm{~mm}$ long was mounted on a cuartz plate using copper clamps. The electrical contects to the sample wete made by using silver dag and the electrical leads ware then soldered to the copper clamps. Measurements were carried aut with a current of about $1 \mu^{A}$ passing thraugh the filament. Such a low current value is impartant to prevent self-heating effects [10]. The voltege drop across the filament was measured directly using a frequency lock anslyzer. The temperature of the quartz plate, which was attached to the head of a clased-cycle cryogenic refrigerator, was varled continubusly from $300 \mathrm{~K}$ to $10 \mathrm{~K}$ with uncertainty of $\pm 0.5 \mathrm{~K}$.

\section{Impedance measurements:}

Carbon fiber strands were crushed to powder and pressed into disc-shaped samples of $2 \mathrm{~cm}$ in diameter and about $1.2 \mathrm{~mm}$ in thickness. Electrical contacts were made by using silver dag and two loads connected to the sample, which was palced insido B shielded metallic box. Since the apparent resistance of the sample wros faund to be about 4 ohms and the apporent copucitance was of the ordes of $1 \mathrm{nt}$, very high trequencies in the $\mathrm{MHz}$ fange were used to abtain appreciable 
and merningful measurements. A to-3575A Gain-phase meter was used to measure the sample impedance and phase angle ot room temperatute in the freguancy regicint $50 \mathrm{KHz}$ to $12 \mathrm{MHz}$.

\section{Resalts and Discussione}

\section{Resistivity resulls"}

When the organic polyactylonitrite (PAN) is converted to carbon fibers, a fibril structure is produced with interesting orientational and electricsl properties. Graphite crystalites are oriented nearly with their basal plenes parallel to the fitur axis. The reported average value of the electrical fesistivity of PRN-based carbon ribers is $10^{-5} \Omega \mathrm{m}$ paralkel to the fiber axis and it is high compared to that of the graphite single crystals parailel to the based plane [7]. The mean values of the dimensians of the crystallite size in high modulus and strength fibers are $L_{c}=50 A^{0}$ (prependiruar to the fiber axis) and $\mathrm{L}_{\mathrm{g}}=450 \mathrm{~A}^{\circ}$ (parallel to the tiber nxis). Furthermore, it was lound [6-9] that the electricul resistance is related to some fiker properties such as orientation of the structural units, interlayer spacing, degree of lattice otdering, and the charge catricrs.

Fig. 1 shows the temperature variation of the resistance, $R$, of the as-you PAN-based carban fibers investigeted in this work. It can be seen from $f$ ig. 1 that the observed resistance-temperatute data can be reasonobly represented by an muthematical fitting-cutve of the form

$$
\frac{1}{R}=\frac{1}{a_{1}+a_{2} T+a_{3} \gamma^{2}}+\frac{1}{a_{4} \exp \left(a_{5} T\right)}
$$

where $a_{1}, \mathrm{~B}_{2}$, etc. are constants.

Nevertheless, these is no theoretical or physical grounds on which such a fittirig carve is based. A plot of the resistivily of the fiber versus the tmonperature may bet more infermative and this is depicted in Fig. 2. The resistivity incteases with decreasing temperature, displeys a slight hump (maximum) at about $35 \mathrm{~K}$, and then decreases upon further Inwering the tempereture. Similat behaviour of the resistivity of PAN-based earbon fibers of about $10 \mathrm{jm}$ in tiametet and heet-treated to $1300^{\prime \prime} \mathrm{C}$ was observed by Spain et al. [10]. These authors have found also that similar tesistivity meximum and behaviaur pecurs in ather PAN-based fibers (Magnamite〉, whereas. the maximum is exhibited at lower temperatures $(25 \mathrm{~K}$ ) in others suxh as Thornel 300 .

- Resistivity data was collected two yeats ngo end a maximum was observed on the resistance-temperature curve. Similat maximum hus teen observed earliet by spain et al. [10] on a PAN-based Celion fibers heat-treated to $1300^{\circ} \mathrm{C}$. Professor Spain sent us kindly his solid stnte communication alter a first draft of this articie was written. 
The increase of the resistivity Bs the temperature is decreased, but with no maximum at low temperatures, was found also by Robson et al. [8] for PAN-based carbon fibers, Bright [9] for mesophase pitch-based carbon fibers, Herinckx [12] for rayon-based carbon fibers and Rappeneau et al. [11] for Rigilor AC and AC carbon fibers. All these carbon tibers were heat-treated to vety high temperatures $\left(<3000^{\circ} \mathrm{C}\right)$. These authors have discussed the fesistivity variation with temperature in terms of semiconductive behaviour. Such a model, however, would lead to a further increase in the resistivity as the temperature is continuously decteased. Therefore, this model might not be applied successtully to our findings though the as-spun PAN-based cartan fibers investigated in this work contain considerable amcunt of metallic impurities $[5,13]$ which may effect the resistivity behaviour of these Celion fibers at low temperatures. A correlation between the crystallite size and the resistivity ratio $\rho_{77} / 9300$ (or the relative graphitic order parameter) may be found from the results of Robson et at. [B] on PAN-based carbon ribers, Fig. 2 yields a resistivity ratio of 1.07 which corresponds to a crysłallite size of about $40^{\circ} \mathrm{A}$ for our Celion PAN-based fibers. The graphitic order parameter, and hence the imperfections, defect levels, crystalline boundaries and the like, govern the behaviour of resistivity and its variation with temperature. The abserved decrease in resistivity with increasing temperature seems difficult to interpret in terms of electran-phonon intersctions.

When the effect of lacalized energy states in the energy band associsted with impurities and/or other defects are assumed to exist in carbon fibers [9, 14 , sorre sort of activation energy would be deduced from the vetietion of resistivity, $\rho$, with temperature [4]. This activation energy may be due to charge carrier activation and/or mobility sctivation Impurity scattering ptocesses, which are usually dominant at temperatures lower than those at which electron-phonon interections are important, would lead to an increase in moblity $u$, and hence $a$ decrease in resistivity, with increasing temperature $\left(i . e, \mu_{m} \mathrm{~T}^{3 / 2}\right.$ ). Our resistivity results do not follow this latter mobility behaviour, but showed an activated confuctian pracess on the In $\rho$ versus $1 / T$ plot over a natrow range on the high temperature side.

It is noteworthy that more measurements (including Hall effect data, thermopower, magnetoresistance) might reveal the actual conduction mechanisms occuring in carbon fibers as these measurements usually give complementary infomative results ta thase of resistivity.

A fairly successful and physically acceptable irnerpretation of the observed resistivity behaviout over the whole temperature tange studied may be achieved if one consider that localization effects are responaible for this hehaviour as was arqued by Spain of al. [10]. These authors have qualitatively discussed such a behaviout in terms of kcalization of electrons at high temperatures due to thermal disorder and delacalization as well as lowering effective mass of electron at low temperstures. They also pointed out that electron-spin interactions would account 


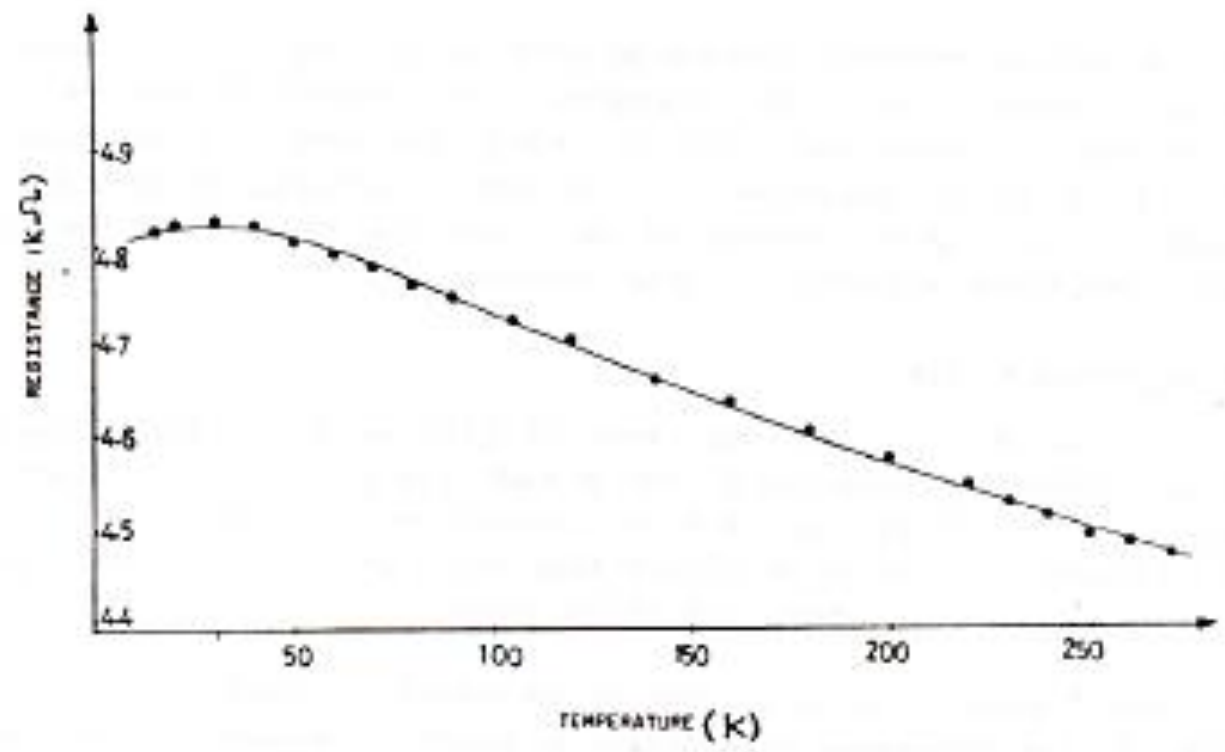

Fig.1t Temperoture variation of tesistance of as-spun PAN-based carbon fiber.

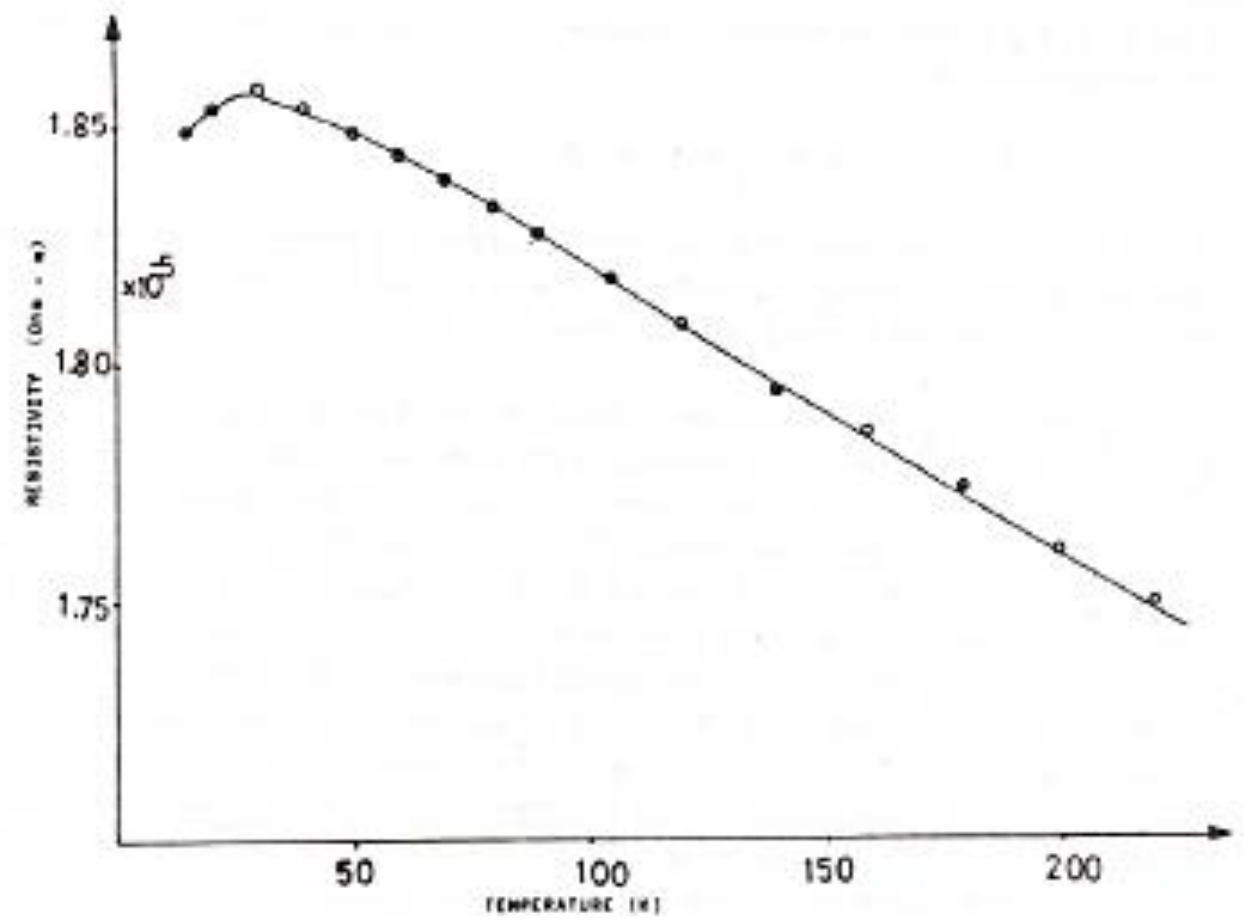

Fig2: Resistivity of as-spun PAN based carbon fiber as a functio of tempersture. 
for the abserved teslstivity maximum as spins may be located at the edges of the ribtans in fibers. A quantitative description of the variation of resistivity, with temperature, $T$, within the localization model [15] yields that the canductivity, $\sigma\langle=1 / \rho\rangle$, is linearly proportional to $T$ at high temperatures. We believe that out experimental data of the rcsistivity of the as-quan PAN-based carbon fibers exhibits such a temperature-dependence of temperatures above $35 \mathrm{~K}$.

\section{AC Impedance Resailts}

An interest in our laboratoty arose to study the ac impedance behaviour for as-spun PAN-based carbon fibers. Such a study may be useful for a better understanding of the electrical and dielectric properties of such carbon fibers impedence measurements wete only made at rocm temperature and for pellet samples prepated fram these tibers aver a wide range of frequencies.

Fig. 3 shows a typical vatiation of the complex impedance, $Z$, and the phase angle, $\emptyset$, of a disc-shaped pellet sample as functian of frequency, $t$, The measured impedance will be teferred to as the apperent impedance since the sample is a porous one. It is cleat from Fig. 3 that the apparent impedance remains ccontant $(=4 \Omega$ ) up to $f=5 \mathrm{MHz}$, beyond which $\mathrm{Z}$ starts to increase monotonically with frequency. On the other hand, the phase angle begins to decrease with increasing frequency at $1 \geqslant 1 \mathrm{MHz}$. Impedance components $Z_{R}$ (real part) and $Z_{1}$ (imarinaty part) were calculated from

$$
z_{R}=Z \operatorname{Cos} \emptyset ; z_{1}=z \sin \theta
$$

A plot of $Z_{1}$ versus $Z_{R}$ gives the so-called complex impedance plot shown in fig. 4. This behaviour of canducting carban fibers is dissimilat to the complex impedance plats coserved in diclectric and other materials [16].

Detailed aralysis of the complex dielectric constant $\epsilon^{*}=\epsilon^{*}-i \epsilon^{\prime \prime}$ shuwed [17] that the apparent real part, ", decreases with trequency nearly as $1 / t^{0.7}$ up to I 5 5 $\times 10^{5} \mathrm{~Hz}$ and then becomes almost constant at higher frequencies as clearly seen in Fig. 5 (a). On the other hand, the epperent imaginary past of the dielectric constant, $f$ ", was faund to vacy inversely with frequancy in the trequency range $50 \mathrm{KHz}$ to $\mathrm{g} \mathrm{MHz}$, beyond which a slight deviation fram this relationship was observed as shown in Fig. 5 (b). Theoretical trestments [1B] predicts that $\epsilon^{\prime \prime}=\sigma 2 \pi \epsilon_{0} t$, where $\epsilon_{0}$ is the petmittivity of free space and $\sigma$ is the ac conductivity of the material. The observed behaviour of $t^{\prime \prime}$ with Irequency suggests that the roomtemperature ac conductivity of as-spun PAN-based catbon libers is frequencyIndependent in the above mentioned frequency tenge. Such a conductivity behaviaut is expected when electeical conduction occurs in extended (Blach) energy states [19]. Nevertheless, we wish to point out that further intensive work is needed to measure the impedance of single Celion fibers parallel and perpendicular to the fiber oxis and as a function of tempetature. This type of study is in progress. 


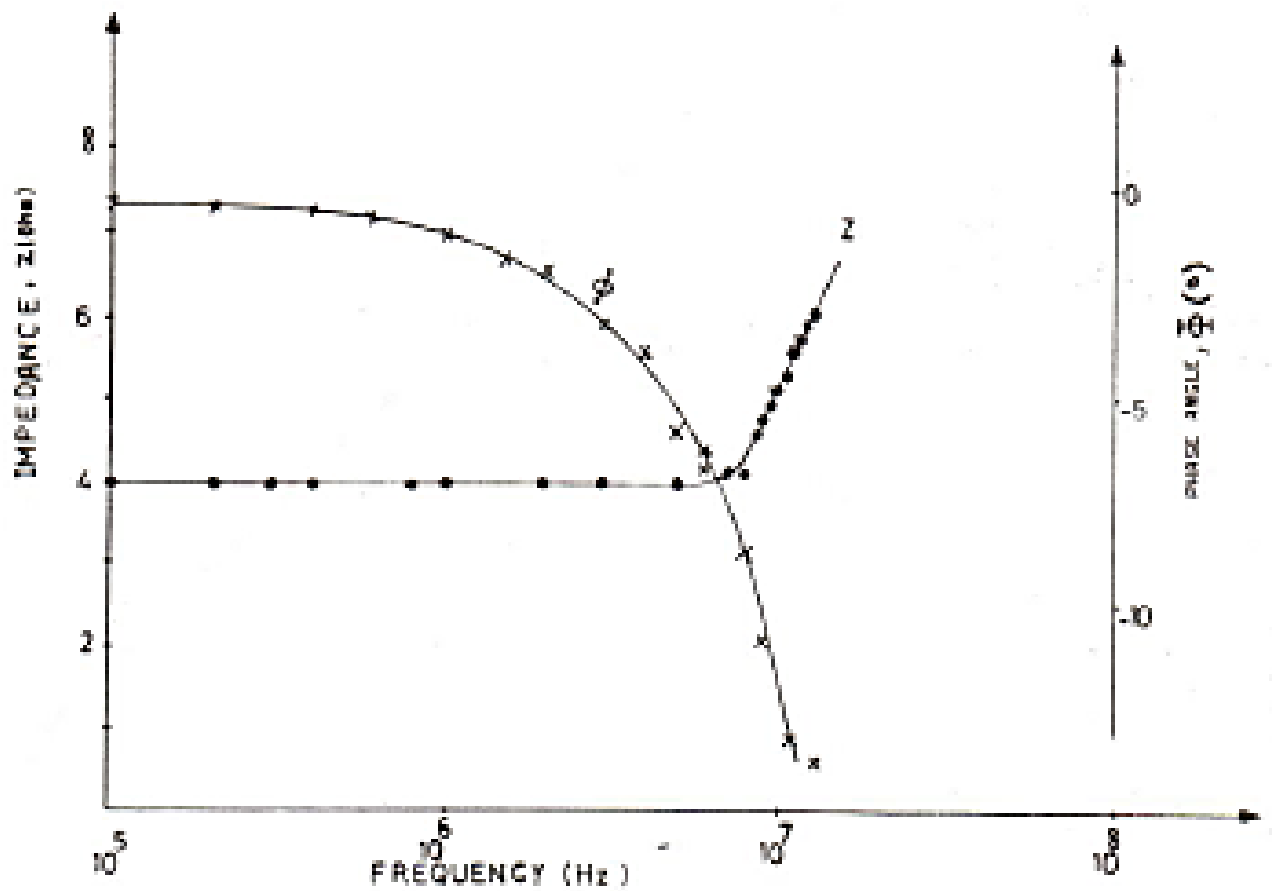

Fig-3: Frequency dependence of Complex impedence, $Z$, and phase angle, $\Phi$, of as-spun based carbon fiber.

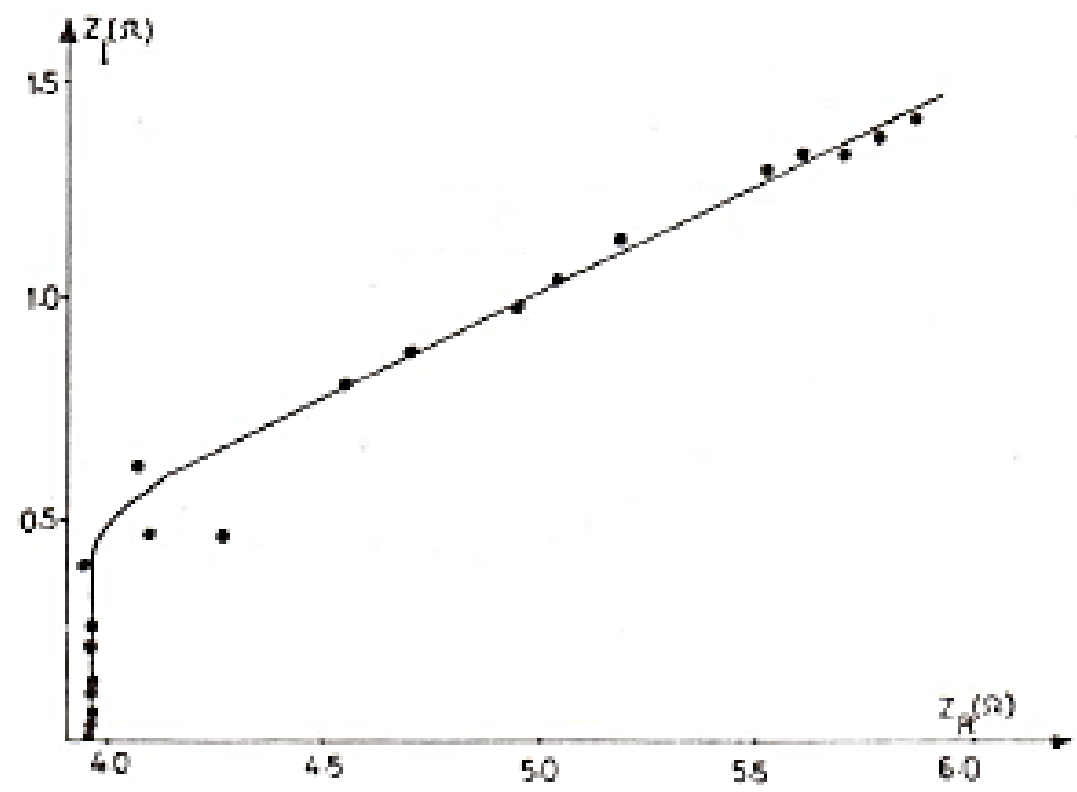

Fiq4: Complex impedance plot of $Z_{1}$ versus $Z_{R}$ for the as-spun PAN based carbon fiber. 


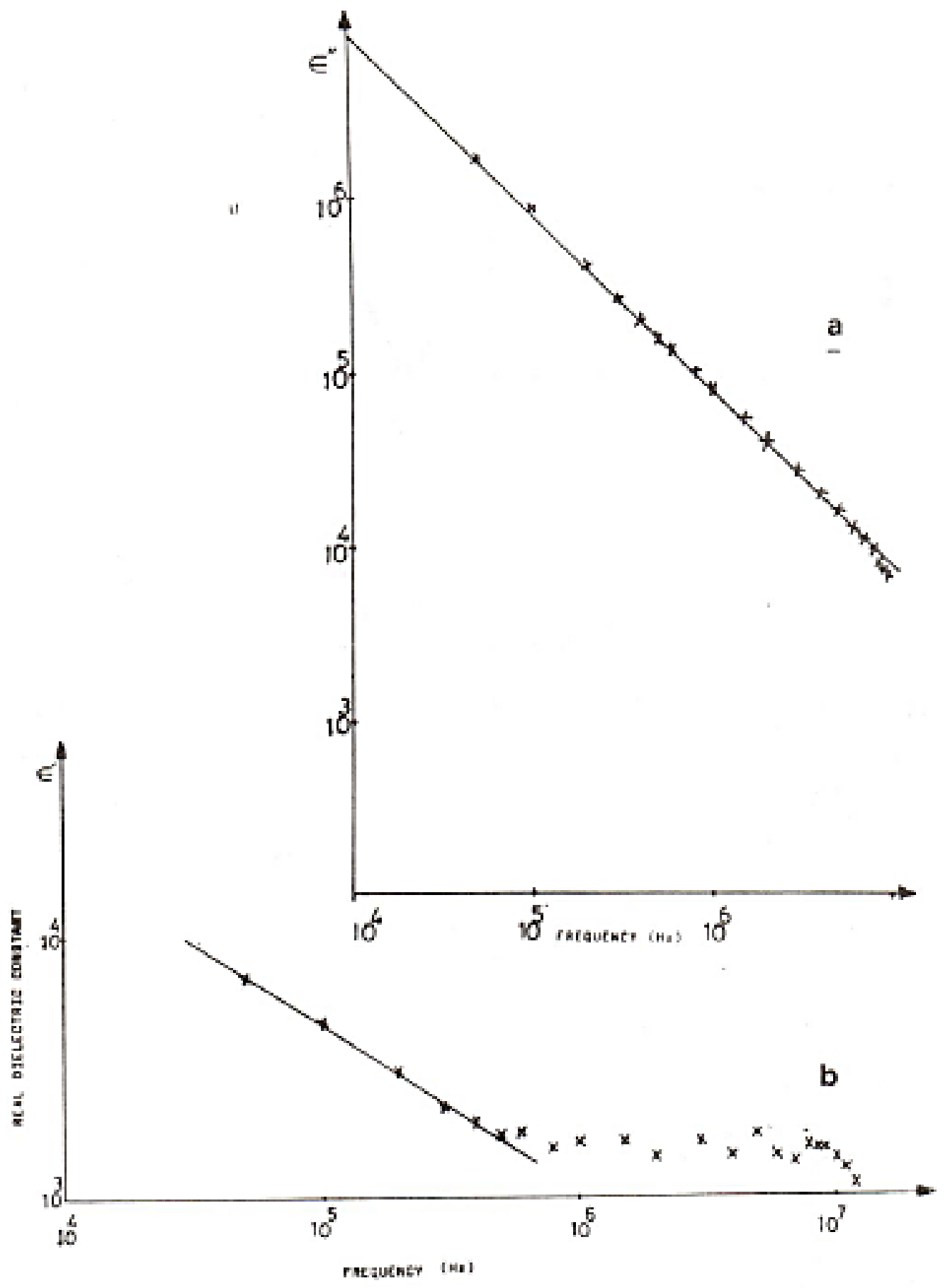

Fig.5: Frecuency vatiation of the real part of thedielectric constant, $E^{\prime}$, (Sa) and imeginaty part, $\epsilon^{\prime \prime},(5 b)$ of the as-spun PAN based carbon fiber. 


\section{Conclusiore}

The electrical resistivity and the toom temperature apparent impedance of high strength as-spun PAN-based carbon fibers were measured as a functian of temperature and frequency, respectively. Several interesting results were abserved.

The resistivity changes with temperature as $1 / T$ for $35 \mathrm{~K}<\mathrm{T}<30 \mathrm{~K}$. This behaviour isattributed to localization effects which ate dominant at high temperatures. A maximum in the resistivity was abserved at $T \sim 35 K$, below which the resistivity seems to foll with further lowering temperature. This interesting feature was interpteted in tetms of increasing delocalization of electrons and lowering their effective mass at low temperatures. It seems that such, resistivity behaviour with temperature occurs in PAN-based carton fibers whether they are heat-treated or not.

Impedsnce behaviour of these carbon fibers is very dissimilar to that observed in dielectric and the like materials. The real part of the dielectric constant was found ta vary as $r^{-0.7}$ below $t \sim 0.5 \mathrm{MHz}$ and being constant at higher frequencies. The observed behaviour of $\epsilon^{\prime \prime}$, the imaginary part of dielectric constant, suggests that the corductivity of the carbon fiber is constant over the whole frequency range studied

\section{Ackanowledgement:}

The ahtaurs wish to thank professor R. Fatris, Dt. J. Mayer, and Dr. N. Saleh for their cooperation. Celanese Research Company is gratefully acknowledged for providing us with high strength as-spun PAN-based corbon fibers investigated in this work.

\section{References}

1. R. Bacon, "Chemistry and Physics of Carbon", Ed. Pd. Waiker, Marcel Dekker, New Yatk, Vol. 9, p 20 (1973).

2. M. Cuigon, A. Oberlin and C. Desarmot, Fibre 5ei. and Tech., 20, 55 (1994).

3. D.T. Johnson, Chemistry and Industry, 1B, 692 (19B2).

4. M.T. Yasir MSc. thesis, Physies Department, Undversity of Jordan (1986); Materials Chem. Phys. (1986-In the Press).

5. I. El-Rlheil, M.1. Yasin, M.S. Ahmad and A.M. Zihlif, Jordan Inter, Clectrical and Electronic Eng. Cof., paper, (April-1985).

6. M. Guigon, A. Oberlin and G. Desarmot, Fibre Sci and Jech, 20, 177 (1984).

7. C. Lubir, "Hnndbook of Composites", Van Nastrand Reirhald Cop., London, Page 211 (1902).

8. D. Robson, F.Y.l. Assinghy, E.S. Cooper and D.JE. Ingram, J. Phys D: Appl. Phys., 6, 1922 (1975). 
9. A.A. Bright and L.S. Singer, Carbon, 17, 59 (1979); 17, 259 (1979).

10. U. Spain, K.J. Volin, H.A. Goldberg and 1. Kalnin, Solid State Comm. 45, 817 (1983); T. Phys. Chem. Solids, 44, 839 (1983).

11. J. Rappeneas, G. Micand, A. Drout, A. Pacault, A. Marchand, and E. Dupart, Carbon, 10, $455(1972)$.

12. C. Herinckx, Carbon, 11, 199 (1973).

13. WaN. Reynold and R. Maretan, Phäl. Trans, R. Soc. London, A 294, 451 (1980).

14. CI. Mostovoi, N.N. Dgunov, Yu. N. Rabotnav, and Yu. P. Anufricv, Mckh, Polim., No. 4, $626(1977)$.

15. G.A. Thamns, Physica, 1778P 118B (1983); R. Mansfield, M. Abdul-Gader and P. Fozooni, Solid-Stete Electronics, 28, 109 (19B5); C.A. Thamna, $\bar{A}$. Kawabata, Y. Ootuk8, S. Katsumoto, S. Kobayashi, and W. Sasaki, Phy. Rev. 8, 26, 2113 (1982).

16. R.N. Ahmed-Bitar, M. Abdul-Gader, A.M. Zihlif, and A. Jaber, J. Electronal. Chern. and Interfac. Electrochem, 143, 121 (1983); M.A. Abu-Samra, M.S. Ahmad and A.M. Zihlit, Egypt. J. Solids, 1, 165 (1985).

17. 11. Regolini and 1.1. Saura, Appli Phys, 54, 1528 (1983); M.M. Abdul-Gadet, K.A. Wishah, Y.M. Mahmud, M. Al-Haj Abdallah, and R.N. Ahmed-Bitar (to be pachlishod).

18. HK. Welsh, 1. Phys, C1A, 5641 (19BS); L. Solymar and D. Walsh, Lectures on the electrical properties of Materials. 2nd ed. (Oxtord Univ. Ptess, Oxfosd, 1979) Chapter 10.

19. P. Negles in Amarphous Semicanductors, editor M.H. Brodaky (Springer-Verleg, Berlin 1979) p. 113. 